\title{
Effects of Silibinin on the Pharmacokinetics of Carvedilol after Oral Administration in Rats
}

\author{
Chong-Ki Lee and Jun-Shik Choi ${ }^{1 \dagger}$ \\ Department of Medical Management, Chodang University, Muan \\ ${ }^{1}$ College of Pharmacy, Chosun University, Gwangju 501-759, Republic of Korea,
}

(Received April 8, $2011 \cdot$ Revised May 12, $2011 \cdot$ Accepted May 23, 2011)

\begin{abstract}
This study was designed to investigate the effects of silibinin on the pharmacokinetics of carvedilol after oral administration of carvedilol in rats. Carvedilol was administered orally $(3 \mathrm{mg} / \mathrm{kg})$ with oral silibinin $(0.3,1.5 \mathrm{or} 6 \mathrm{mg} /$ $\mathrm{kg}$ ) and intravenously $(1 \mathrm{mg} / \mathrm{kg})$ to rats. The effects of silibinin on P-glycoprotein (P-gp) and cytochrome P450 (CYP) $2 \mathrm{C} 9$ and CYP2D6 activity were also evaluated. Silibinin inhibited CYP2C9 and CYP2D6 enzyme activity with 50\% inhibition concentration $\left(\mathrm{IC}_{50}\right)$ of $5.2 \mu \mathrm{M}$ and $85.4 \mu \mathrm{M}$, respectively. In addition, silibinin significantly enhanced the cellular accumulation of rhodamine-123 in MCF-7/ADR cells overexpressing P-gp. Compared with the control group, the area under the plasma concentration-time curve was significantly increased by $36.3-57.1 \%$, and the peak concentration was significantly increased by $51.1-88.5 \%$ in the presence of silibinin after oral administration of carvedilol. Consequently, the relative bioavailability of carvedilol was increased by 1.13 - to 1.57 -fold and the absolute bioavailability was significantly increased by $38.6-59.7 \%$. The time to reach peak concentration and the terminal half-life were not significant. The enhanced oral bioavailability of carvedilol may result from inhibition of CYP2C9-mediated metabolism and P-gp-mediated efflux of carvedilol rather than inhibition of CYP2D6-mediated metabolism in the intestine and/or in the liver by silibinin.
\end{abstract}

Key words - Carvedilol, Silibinin, CYP2C9, CYP2D6, P-gp, Pharmacokinetics, Bioavailability, Rats

Carvedilol is an arylethanolamine and has nonspecific $\beta$ and $\alpha_{1}$ - adrenergic blocking effects (Bristow et al., 1992). Carvedilol also reduces the release of endothelin and scavenges free radicals of oxygen (Feuerstein et al., 1997). It is used to treat systemic arterial hypertension (Cournot et al., 1992; Lund-Johansen et al., 1992) and congestive heart failure (DasGupta et al., 1991) and is purported to improve exercise capacity (Hampton, 1996; Cleland et al., 1996) and longevity in humans (Bristow et al., 1996).

Carvedilol, (( \pm )-1-carbazol-4-yloxy)-3-[[2-(omethoxyphenoxy) ethyl]-amino]-2-propanol), an antihypertensive and antianginal compound, which combines nonselective beta-adrenoceptor blocking and vasodilator properties with intrinsic sympathomimetic activity (von Mollendorff E et al., 1986; Frishman, 1998). It is also used to reduce mortality in patients with left ventricular dysfunction following myocardial infarction (Abshagen, 1987). Carvedilol is well absorbed from the gastrointestinal tract, but is subject to considerable first-pass metabolism in the intestinal and/or liver (McTavish et al., 1993; Morgan, 1994). Carvedilol is more than $98 \%$ bound to plasma proteins. Carvedilol is metabolized by both oxidation

\footnotetext{
Corresponding Author:

Tel : +82-62-230-6365, E-mail : jsachoi@chosun.ac.kr

DOI : 10.4333/KPS.2011.41.3.153
}

and conjugation pathways in the liver into some metabolites (Neugebauer et al., 1987; Neugebauer and Neubert, 1991). The oxidation pathways are mainly catalyzed by CYP2C9 and CYP2D6 enzymes in human (McTavish et al., 1993; Morgan, 1994; Oldham and Clarke, 1997), and then CYP2D6 is responsible for the formation of 4'-hydroxy carvedilol and 5'hydroxy carvedilol, and both metabolites are excreted into urine (Neugebauer and Neubert, 1991). Carvedilol is also a substrate of P-gp (Bart et al., 2005). Since carvedilol is a substrate of both CYP enzymes and P-gp, the modulation of CYP and P-gp activities may cause the significant changes in the pharmacokinetic profile of carvedilol.

Flavonoids represent a group of phytochemicals that are produced by various plants in high quantities (Dixon and Steel, 1999). They exhibit a wide range of beneficial biological activities including antioxidative, radical scavenging, antiatherosclerotic, antitumor and antiviral effects (Nijveldt et al., 2001). There is increasing evidence that the inadvertent overproduction of reactive oxygen species may result in oxidative tissue injury that overcomes the protective defense mechanism against oxidants (Takahama, 1985). They are also implicated in some diseases such as cardiovascular disorders, chronic gut inflammation, cancer and AIDS (Ohnishi and Bannai, 1993; Alarcon de la Lastra et al., 1994).

Silymarin, a flavonoid complex, is extracted from seeds of 
the milk thistle (Silybum marianum L.), which is a medicinal plant widely used in traditional European medicine (Morazzoni and Bombardelli, 1995). Silymarin has strong antioxidant activity (Zhao et al., 2000) and exhibits cytoprotective, antiinflammatory, and anticarcinogenic effects (Katiyar et al., 1997). Silibinin is the major and most active component in silymarin, comprising $60-70 \%$ of silymarin (Kosina et al., 2005). Kosina et al. (2005) have reported that silibinin inhibits human CYP 1A2 and 3A4, while Zuber et al. (2002) found that silibinin inhibits human CYP 2D6, 2C9 and 3A4. Thus, the inhibitory effects of silibinin against human CYP enzymes remain somewhat controversial. Silibinin is an inhibitor of $\mathrm{P}$ gp in the KB/MDR cell line (Dzubák et al., 2006), but the inhibitory effect of silibinin against P-gp is ambiguous. Therefore, we re-evaluated the inhibition of CYP enzyme activity and P-gp activity by silibinin using the CYP inhibition assay and the rhodamine-123 retention assay in P-gp-overexpressing MCF-7/ADR cells.

Given that the bioavailability of carvedilol is mainly affected by CYP2C9 and P-gp during first-pass metabolism, silibinin could be expected to improve the bioavailability of carvedilol.

Silibinin and carvedilol sometimes may be prescribed as a combination therapy for treatment of cardiovascular diseases. However, the possible effects of silibinin on the bioavailability and pharmacokinetics of carvedilol in rats have not been reported in vivo. Therefore, the aim of this study was to investigate the effects of silibinin on CYP2C9, CYP2D6 and P-gp activity and the bioavailability or pharmacokinetics of carvedilol in rats.

\section{Materials and Methods}

\section{Chemicals and apparatus}

Carvedilol, silibinin and nimodipine [an internal standard for high-performance liquid chromatograph (HPLC) analysis for carvedilol] were purchased from Sigma-Aldrich Co. (St. Louis, MO, USA). HPLC grade acetonitrile was acquired from Merck Co. (Darmstadt, Germany). Other chemicals for this study were of reagent grade.

Apparatuses used in this study were a HPLC equipped with a Waters 1515 isocratic HPLC Pump, a Waters 717 plus autosampler and a Waters ${ }^{\mathrm{TM}} 474$ scanning fluorescence detector (Waters Co., Milford, MA, USA), a HPLC column temperature controller (Phenomenex Inc., CA, USA), a Bransonic ${ }^{\circledR}$ Ultrasonic Cleaner (Branson Ultrasonic Co., Danbury, CT, USA), a vortex-mixer (Scientific Industries Co., NY, USA) and a high-speed micro centrifuge (Hitachi Co., Tokyo, Japan).

\section{Animal experiments}

Male Sprague-Dawley rats of 7-8 weeks of age (weighing 270-300 g) were purchased from Dae Han Laboratory Animal Research Co. (Choongbuk, Republic of Korea) and given free access to a commercial rat chow diet (No. 322-7-1; Superfeed Co., Gangwon, Republic of Korea) and tap water ad libitum. The animals were housed (two rats per cage) in a clean room maintained at a temperature of $22 \pm 2^{\circ} \mathrm{C}$ and relative humidity of $50-60 \%$, with $12 \mathrm{~h}$ light and dark cycles. The rats were acclimated under these conditions for at least 1 week. All animal studies were performed in accordance with the "Guiding Principles in the Use of Animals in Toxicology" adopted by the Society of Toxicology (USA) and the Animal Care Committee of Chosun University (Gwangju, Republic of Korea) approved the protocol of this animal study. The rats were fasted for at least $24 \mathrm{~h}$ prior to beginning the experiments and had free access to tap water. Each animal was anaesthetized lightly with ether. The left femoral artery and vein were cannulated using polyethylene tubing (SP45, I.D. $0.58 \mathrm{~mm}$, O.D. $0.96 \mathrm{~mm}$; Natsume Seisakusho Co. LTD., Tokyo, Japan) for blood sampling and i.v. injection, respectively.

\section{Oral administration of carvedilol}

The rats were divided into five groups $(n=6$, each): an oral group ( $3 \mathrm{mg} / \mathrm{kg}$ of carvedilol dissolved in water; homogenized at $36^{\circ} \mathrm{C}$ for $30 \mathrm{~min} ; 3.0 \mathrm{~mL} / \mathrm{kg}$ ) without (control) or with 0.3 , 1.5 or $6 \mathrm{mg} / \mathrm{kg}$ of oral silibinin, and an i.v. group $(1 \mathrm{mg} / \mathrm{kg}$ of carvedilol, dissolved in $0.9 \% \mathrm{NaCl}$ solution; homogenized at $36^{\circ} \mathrm{C}$ for $30 \mathrm{~min} ; 1.5 \mathrm{~mL} / \mathrm{kg}$ ). Silibinin was orally administered $30 \mathrm{~min}$ prior to oral administration of carvedilol. Oral carvedilol was administered through a feeding tube, and carvedilol for i.v. administration was injected through the femoral vein within $0.5 \mathrm{~min}$. A $0.4-\mathrm{mL}$ blood sample was collected into heparinized tubes from the femoral artery at $0,0.1,0.25,0.5,1,2$, $4,8,12$ and $24 \mathrm{~h}$ after intravenous infusion and at $0,0.25,0.5$, $1,2,4,8,12$ and $24 \mathrm{~h}$ after oral administration. The blood samples were centrifuged $(13,000 \mathrm{rpm}, 5 \mathrm{~min})$, and the plasma samples were stored at $-40^{\circ} \mathrm{C}$ until HPLC analysis of carvedilol. Rats were infused with approximately $1 \mathrm{~mL}$ of whole blood collected from untreated rats via the femoral artery at $0.5,2$ and $8 \mathrm{~h}$ to replace the blood loss due to blood sampling.

\section{HPLC assay}

The plasma concentrations of carvedilol were determined by the HPLC assay method reported by Zarghi et al. (2007). Briefly, $50 \mu \mathrm{L}$ of dihydroerogostine $(20 \mu \mathrm{g} / \mathrm{mL}$ dissolved in methanol; an internal standard) and $0.5 \mathrm{~mL}$ of acetonitrile were 
added to a $0.2 \mathrm{~mL}$ aliquot of the plasma in a $2.0 \mathrm{~mL}$ polypropylene microtube. The mixture was then stirred for $10 \mathrm{~min}$ and centrifuged (13,000 rpm, $10 \mathrm{~min})$. A $0.5 \mathrm{~mL}$ aliquot of the organic layer was transferred to a clean test tube and evaporated under a gentle stream of nitrogen gas at $35^{\circ} \mathrm{C}$. The residue was reconstituted in a $150 \mu \mathrm{L}$ of the mobile phase and centrifuged $(13,000 \mathrm{rpm}, 5 \mathrm{~min})$. The resulting mixture was then vigorously vortex-mixed for $5 \mathrm{~min}$ and centrifuged at $13,000 \mathrm{rpm}$ for $5 \mathrm{~min}$. A $50-\mu \mathrm{L}$ aliquot of the supernatant was injected into the HPLC system. Chromatographic separations were achieved using a Chromolith Performance (RP-18e, $100 \mathrm{~mm} \times 4.6 \mathrm{~mm}$ ) column from Merck (Darmstadt, Germany). The mobile phase consisted of $0.01 \mathrm{M}$ disodium hydrogen

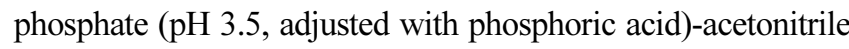
$(75.7: 24.3, \mathrm{v} / \mathrm{v})$. The flow rate of the mobile phase was maintained at $2.0 \mathrm{~mL} / \mathrm{min}$. Chromatography was performed at of $25^{\circ} \mathrm{C}$, which was regulated by an HPLC column temperature controller. The fluorescence detector was operated at an excitation wavelength of $240 \mathrm{~nm}$ with an emission wavelength of $340 \mathrm{~nm}$. The retention times at a flow rate of $2 \mathrm{~mL} / \mathrm{min}$ were as follows: carvedilol at $8.076 \mathrm{~min}$ internal standard at 9.305 min. The lower limit of quantification for carvedilol in rat plasma was $10 \mathrm{ng} / \mathrm{mL}$. The coefficient of the variation of carvedilol was less than $14.3 \%$.

\section{Pharmacokinetic analysis}

The plasma concentration data were analyzed by the noncompartmental method using WinNonlin software version 4.1 (Pharsight Co., Mountain View, CA, USA). The elimination rate constant $\left(\mathrm{K}_{\mathrm{el}}\right)$ was calculated by log-linear regression of carvedilol concentration data during the elimination phase, and the terminal half-life $\left(t_{1 / 2}\right)$ was calculated by $0.693 / K_{\mathrm{el}}$. The peak concentration $\left(\mathrm{C}_{\max }\right)$ and the time to reach peak concentration $\left(T_{\max }\right)$ of carvedilol in plasma were obtained by visual inspection of the data from the concentration-time curve. The area under the plasma concentration-time curve $\left(\mathrm{AUC}_{0-t}\right)$ from time zero to the time of last measured concentration $\left(\mathrm{C}_{\text {last }}\right)$ was calculated by the linear trapezoidal rule. The AUC zero to infinity $\left(\mathrm{AUC}_{0-\infty}\right)$ was obtained by the addition of $\mathrm{AUC}_{0-\mathrm{t}}$ and the extrapolated area determined by $\mathrm{C}_{\text {last }} /$ $\mathrm{K}_{\mathrm{el}}$. Total body clearance (CL/F) was calculated by Dose/ AUC. The absolute bioavailability (A.B.) of carvedilol was calculated by $\mathrm{AUC}_{\text {oral }} / \mathrm{AUC}_{\mathrm{i} . \mathrm{v} .} \times$ Dose $_{\mathrm{i} . \mathrm{V}} /$ Dose $_{\text {oral }} \times 100$, and the relative bioavailability (R.B.) of carvedilol was estimated by $\mathrm{AUC}_{\text {with silibinin }} / \mathrm{AUC}_{\text {control }} \times 100$.

\section{CYP2C9 and CYP2D6 inhibition assay}

The assays of inhibition on human 2C9 and CYP2D6 enzyme activities were performed in a multiwell plate using CYP inhibition assay kit (GENTEST, Woburn, MA) as described previously (Crespi et al., 1997). Briefly, human CYP enzymes were obtained from baculovirus-infected insect cells. CYP substrates (7-MFC for CYP2C9) were incubated with or without test compounds in the enzyme/substrate contained buffer consisting of 1 pmol of P450 enzyme and NADPH generating system (1.3 mM NADP, $3.54 \mathrm{mM}$ glucose 6-phosphate, $0.4 \mathrm{U} / \mathrm{mL}$ glucose 6-phosphate dehydrogenase and 3.3 $\mathrm{mM} \mathrm{MgCl}_{2}$ ) in a potassium phosphate buffer (pH 7.4). Reactions were terminated by adding stop solution after $45 \mathrm{~min}$ incubation. Metabolite concentrations were measured by spectrofluorometer (Molecular Device, Sunnyvale, CA) set at an excitation wavelength of $409 \mathrm{~nm}$ and an emission wavelength of $530 \mathrm{~nm}$. Positive control ( $2 \mu \mathrm{M}$ sulfaphenazole for CYP2C9) was run on the same plate and produced $99 \%$ inhibition. All experiments were performed in duplicate, and results are expressed as the percent of inhibition.

\section{Rhodamine-123 retention assay}

MCF-7/ADR cells were seeded in 24-well plates. At $80 \%$ confluence, the cells were incubated in FBS-free DMEM for $18 \mathrm{~h}$. The culture medium was changed to Hanks' balanced salt solution and the cells were incubated at $37^{\circ} \mathrm{C}$ for $30 \mathrm{~min}$. After incubation of the cells with $20 \mu \mathrm{M}$ rhodamine- 123 for $90 \mathrm{~min}$, the medium was completely removed. The cells were then washed three times with ice-cold phosphate buffer $(\mathrm{pH}$ 7.0) and lysed in lysis buffer. The rhodamine-123 fluorescence in the cell lysates was measured using excitation and emission wavelengths of 480 and $540 \mathrm{~nm}$, respectively. Fluorescence values were normalized to the total protein content of each sample and presented as the ratio to controls.

\section{Statistical analysis}

All mean values are presented with their standard deviation (Mean \pm S.D.). Statistical analysis was conducted using oneway ANOVA followed by a posteriori testing with Dunnett's correction. Differences were considered significant at a level of $\mathrm{P}<0.05$ and $\mathrm{P}<0.01$.

\section{Results}

\section{Inhibition of CYP2C9 and CYP2D6 activity}

The inhibitory effect of silibinin on CYP2C9 activity and CYP2D6 activity are shown in Figure 1. Silibinin inhibited CYP2C9 and CYP2D6 activity in a concentration-dependent manner. Silibinin inhibited CYP2C9 and CYP2D6 with $\mathrm{IC}_{50}$ values of $5.2 \mu \mathrm{M}$ and $85.4 \mu \mathrm{M}$, respectively. $\mathrm{IC}_{50}$ values of 

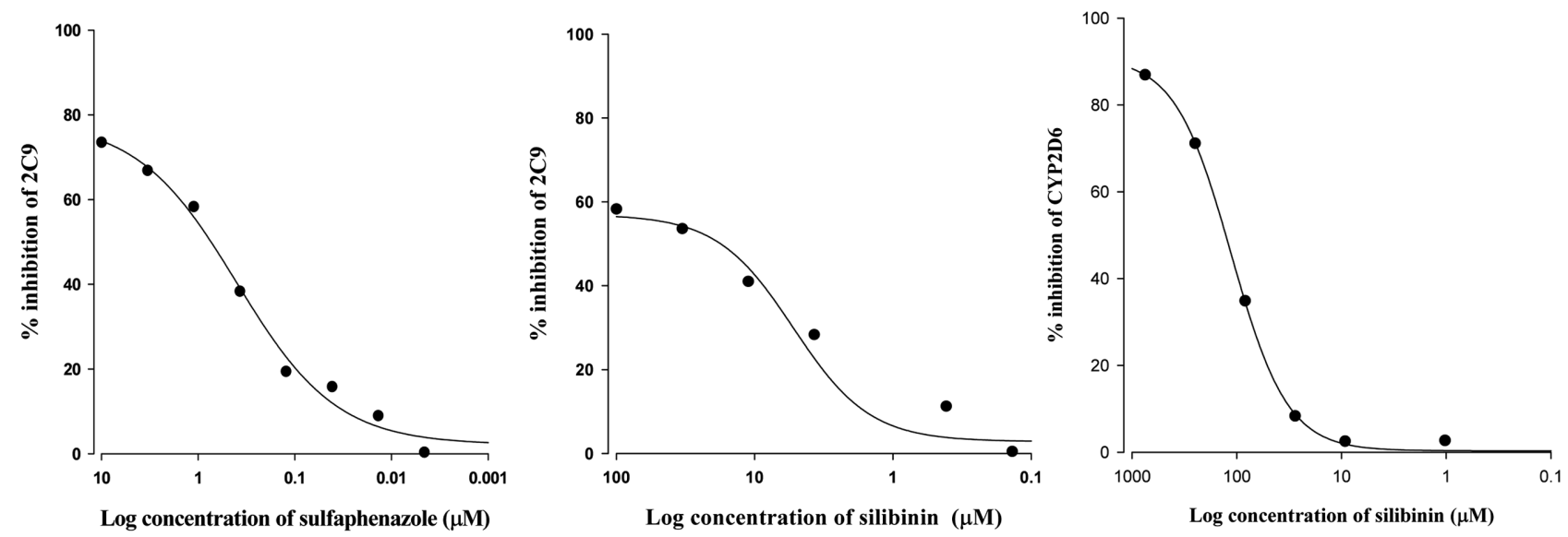

Figure 1. Inhibitory effect of sulfaphenazole and silibinin on the CYP2C9 and CYP2D6 activity. All experiments were performed in duplicate, and results are expressed as the percent of inhibition.

Positive control ( $2 \mu \mathrm{M}$ sulfaphenazole for CYP2C9) was $0.4 \mu \mathrm{M}$. But, silibinin inhibited CYP2D6 activity very weakly.

\section{Rhodamine-123 retention assay}

As shown in Figure 2, accumulation of rhodamine-123, a Pgp substrate, was enhanced in MCF-7/ADR cells overexpressing P-gp compared to that in MCF-7 cells lacking P-gp. The concurrent use of silibinin enhanced the cellular uptake of rhodamine 123 , and showed statistically significant $(100 \mu \mathrm{M}$, $\mathrm{P}<0.01)$ increase. This result suggests that silibinin significantly inhibits P-gp activity.

\section{Effects of silibinin on plasma concentrations of oral} carvedilol

The mean plasma concentration-time profiles of oral carvedilol in the presence or absence of silibinin are illustrated in Figure 3. The mean pharmacokinetic parameters of carvedilol are also summarized in Table I, Figure 3 shows the plasma concentration-time profiles of carvedilol after oral administration of $3 \mathrm{mg} / \mathrm{kg}$ of carvedilol in rats with or without silibinin

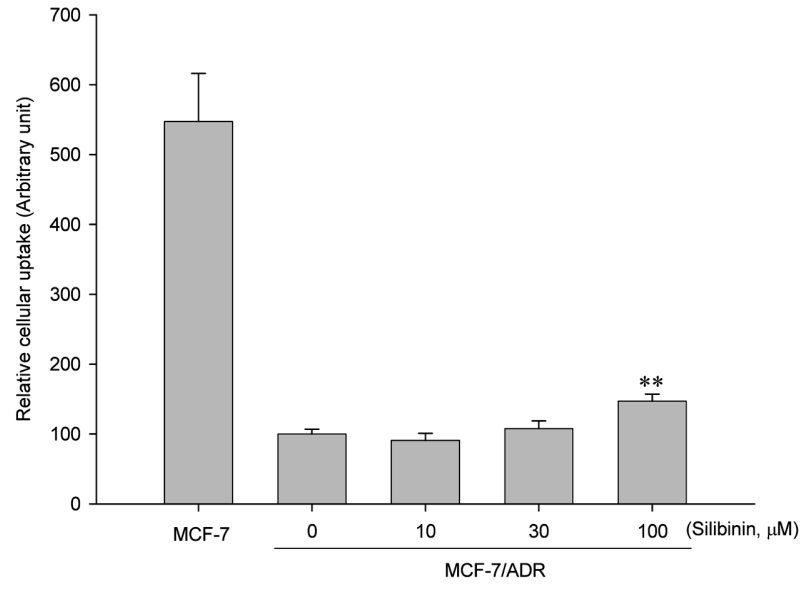

Figure 2. Effect of silibinin on the cellular accumulation of rhodamine-123 in MCF-7 and MCF-7/ADR cells. Data represents mean \pm S.D. of 6 separate samples (significant versus control MCF7 cells, $\left.{ }^{* *} \mathrm{P}<0.01\right)$.

$(0.3,1.5$ or $6 \mathrm{mg} / \mathrm{kg})$, and the pharmacokinetic parameters of oral carvedilol are summarized in Table I. The area under the plasma concentration-time curve was significantly $(1.5 \mathrm{mg} / \mathrm{kg}$,

Table I. Mean ( \pm S.D.) Pharmacokinetic Parameters of Carvedilol after Intravenous (1 mg/kg) and Oral (3 mg/kg) Administration of Carvedilol with Silibinin (0.3, 1.5 and $6 \mathrm{mg} / \mathrm{kg}$ ) to Rats

\begin{tabular}{lccccc}
\hline \hline \multirow{2}{*}{ Parameters } & Control & \multicolumn{4}{c}{ Carvedilol+silibinin } \\
\cline { 2 - 5 } & & $0.3 \mathrm{mg} / \mathrm{kg}$ & $1.5 \mathrm{mg} / \mathrm{kg}$ & $6 \mathrm{mg} / \mathrm{kg}$ & i.v. \\
\hline $\mathrm{AUC}(\mathrm{ng} \cdot \mathrm{h} / \mathrm{mL})$ & $1608 \pm 299.1$ & $1824 \pm 333$ & $2191 \pm 435^{*}$ & $2526 \pm 567^{* *}$ & $1817 \pm 393$ \\
$\mathrm{C}_{\max }(\mathrm{ng} / \mathrm{mL})$ & $131 \pm 22.6$ & $145 \pm 25$ & $198 \pm 40^{*}$ & $247 \pm 51^{* *}$ & \\
$\mathrm{~T}_{\max }(\mathrm{h})$ & 0.5 & 0.5 & 0.5 & 0.5 & \\
$\mathrm{t}_{1 / 2}(\mathrm{~h})$ & $10.0 \pm 1.8$ & $10.4 \pm 2.1$ & $11.1 \pm 2.2$ & $11.5 \pm 2.4$ & $8.1 \pm 1.4$ \\
A.B.(\%) & $29 \pm 5.6$ & $33.5 \pm 5.8$ & $40.2 \pm 7.9^{*}$ & $46.3 \pm 8.5^{* *}$ & \\
R.B.(\%) & 100 & 113 & 136 & 157 & \\
\hline
\end{tabular}

Mean \pm S.D., $\mathrm{n}=6 . * \mathrm{P}<0.05, * * \mathrm{P}<0.01$, compared with the control group.

AUC: area under the plasma concentration-time curve from $0 \mathrm{~h}$ to infinity, $\mathrm{C}_{\max }$ : peak plasma concentration, $\mathrm{T}_{\max }$ : time to reach peak concentration, $\mathrm{t}_{1 / 2}$ : half-life, A.B.: absolute bioavailability, R.B. : relative bioavailability compared to the control group. 


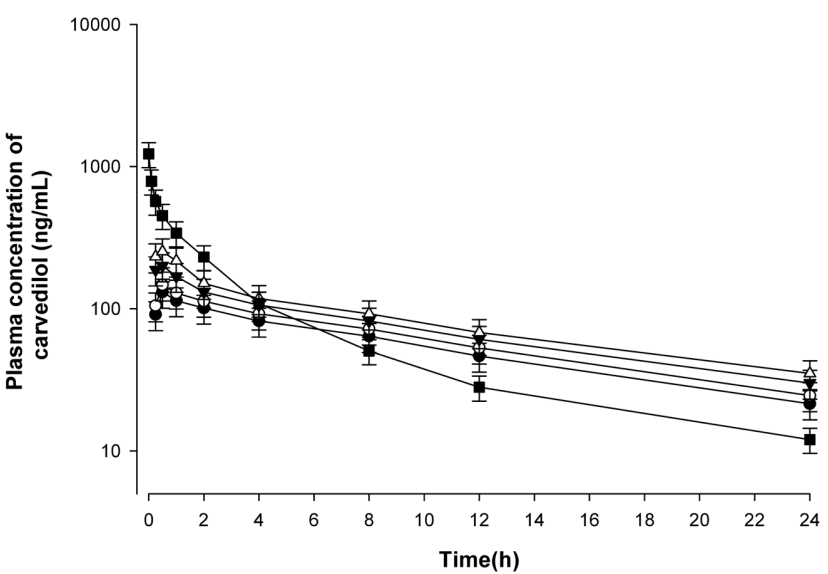

Figure 3. Mean plasma concentration-time profiles of carvedilol after oral administration of carvedilol $(3 \mathrm{mg} / \mathrm{kg})$ without or with silibinin $(0.3,1.5$ or $6 \mathrm{mg} / \mathrm{kg})$ and after i.v. administration of carvedilol $(1 \mathrm{mg} / \mathrm{kg})$ to rats. Bars represent the standard deviation ( $=6$, , $(\bigcirc) 3 \mathrm{mg} / \mathrm{kg}$ of oral carvedilol, $(\bigcirc)$ with $0.3 \mathrm{mg} / \mathrm{kg}$ of silibinin, $(\boldsymbol{\nabla})$ with $1.5 \mathrm{mg} / \mathrm{kg}$ of silibinin, $(\triangle)$ with $6 \mathrm{mg} / \mathrm{kg}$ of silibinin and (ם) $1 \mathrm{mg} / \mathrm{kg}$ of i.v. carvedilol to rats.

$\mathrm{P}<0.05 ; 6 \mathrm{mg} / \mathrm{kg}, \mathrm{P}<0.01)$ increased by $36.3-57.1 \%$, and the peak concentration was significantly $(1.5 \mathrm{mg} / \mathrm{kg}, \mathrm{P}<0.05$; $6 \mathrm{mg} / \mathrm{kg}, \mathrm{P}<0.01)$ increased by $51.1-88.5 \%$ in the presence of silibinin after oral administration of carvedilol. Consequently, the relative bioavailability (R.B.) of carvedilol was increased by $1.13-$ to 1.57 -fold, and the absolute bioavailability of carvedilol in the presence of silibinin (40.2-46.3\%) was significantly higher $(1.5 \mathrm{mg} / \mathrm{kg}, \mathrm{P}<0.05 ; 6 \mathrm{mg} / \mathrm{kg}, \mathrm{P}<0.01)$ than that in the control group (29\%). However, there were no significant changes in the half-life and $\mathrm{T}_{\max }$ of carvedilol in the presence of silibinin.

\section{Discussion}

Inhibitors of both CYP2C9, CYP2D6 and P-gp should have a great impact on the bioavailability and pharmacokinetics of many drugs which is substrat of CYP2C9, CYP2D6 and P-gp. Based on the broad overlap in the substrate specificities as well as co-localization in the small intestine, the primary site of absorption for orally administered drugs, CYP3A4, CYP2C9, CYP2D6 and P-gp have been recognized as a concerted barrier to the drug absorption (Cummins et al., 2002; Benet et al., 2003).

Induction or inhibition of intestinal CYPs may be responsible for significant drug interactions that one agent decreases or increases the bioavailability and absorption rat constant of a concurrently administered drug (Kaminsky and Fasco, 1991).

The inhibitory effect of silibinin against CYP2C9-and CYP2D6-mediated metabolism were confirmed by the employment of recombinant CYP2C9 and CYP2D6 enzyme. As shown in Figure 1, silibinin exhibited inhibitory effect against CYP2C9-and CYP2D6-mediated metabolism with $\mathrm{IC}_{50}$ of $5.2 \mu \mathrm{M}$ and $85.4 \mu \mathrm{M}$, respectively. However, silibinin inhibited CYP2D6 activity very weakly.

Furthermore, the cell-based assay using rhodamine-123 indicated that silibinin $(100 \mu \mathrm{M})$ significantly $(\mathrm{P}<0.01)$ inhibited P-gp-mediated efflux (Figure 3). These results are consistent with the previous report (Zuber et al., 2002; Dzubák et al., 2006). Therefore, the pharmacokinetic characteristics of carvedilol were evaluated in the absence and presence of silibinin in rats. Human $\mathrm{CYP} 2 \mathrm{C} 9$ and $3 \mathrm{~A} 4$ and rat $\mathrm{CYP} 2 \mathrm{C} 11$ and $3 \mathrm{~A} 1$ have 77 and $73 \%$ protein homology, respectively (Lewis, 1996). Rats were selected as an animal model in this study to evaluate the potential pharmacokinetic interactions mediated by $\mathrm{CYP} 2 \mathrm{C}$, although there may be some difference in enzyme activity between rat and human (Cao et al., 2006). Therefore, silibinin might possible increase absorption of carvedilol in the intestine through the inhibition of P-gp and CYP2C9. The area under the plasma concentration-time curve was significantly increased by $36.3-57.1 \%$, and the peak concentration was significantly increased by $51.1-88.5 \%$ in the presence of silibinin after oral administration of carvedilol. Consequently, the relative bioavailability of carvedilol was increased by 1.13 - to 1.57 -fold, and the absolute bioavailability was significantly increased by $38.6-59.7 \%$.

In addition to its extensive metabolism by CYP2C9, carvedilol appeared to be the substrate of P-gp, suggesting that P-gp and CYP2C9 should act synergistically to limit the oral bioavailability of carvedilol (Saeki et al., 1993). Studies on drug interactions with grapefruit juice have provided much understanding of the role of intestinal CYP450 in the absorption of orally administered drugs. CYP2C9 is the predominant P450 present in the small intestine (Kolars et al., 1992).

\section{Conclusion}

The increased bioavailability of carvedilol might be due to inhibition of P-gp efflux and CYP2C9-madiated metabolism of carvedilol more than inhibition of CYP2D6-madiated metabolism of carvedilol in the intestine and/or in the liver by silibinin. Therefore, concomitant use of silibinin or silibinincontaining dietary supplements with carvedilol will require close monitoring for potential drug interactions.

\section{References}

Abshagen, U., 1987. A new molecule with vasodilating and $\beta$ - 
adrenoceptor blocking properties. J. Cardiovasc. Pharmacol. 10, 23-32.

Alarcon de la Lastra, C., Martin, M.J., Motilva, V., 1994. Antiulcer and gastroprotective effects of quercetin: a gross and histologic study. Pharmacology 48, 5662.

Bart, J., Dijkers, E.C., Wegman, T.D., de Vries, E.G., van der Graaf, W.T., Groen, H.J., Vaalburg, W., Willemsen, A.T., Hendrikse, N.H., 2005. New positron emission tomography tracer $[(11) C]$ carvedilol reveals P-glycoprotein modulation kinetics. Br. J. Pharmacol. 145, 1045-51.

Benet, L.Z., Cummins, C.L., Wu, C.Y., 2003. Transporter-enzyme interactions: implications for predicting drug-drug interactions from in vitro data. Curr. Drug Metab. 4, 393-398.

Bristow, M.R., Gilbert, E.M., Abraham, W.T., Adams, K.F., Fowler, M.B., Hershberger, R.E., Kubo, S.H., Narahara, K.A., Ingersoll, H., Krueger, S., Young, S., Shusterman, N., 1996. Carvedilol produces dose-related improvements in left ventricular function and survival in subjects with chronic heart failure. MOCHA Investigators. Circulation 94, 2807-2816.

Bristow, M.R., Larrabee, P., Minobe, W., Roden, R., Skerl, L., Klein, J., Handwerger, D., Port, J.D., Müller-Beckmann, B., 1992. Receptor pharmacology of carvedilol in the human heart. J. Cardiovasc. Pharmacol. 19, S68-80.

Cao, X., Gibbs, S.T., Fang, L., Miller, H.A., Landowski, C.P., Shin, H.C., Lennernas, H., Zhong, Y., Amidon, G.L., Yu, L.X., Sun, D., 2006. Why is it challenging to predict intestinal drug absorption and oral bioavailability in human using rat model. Pharm. Res. 23, 1675-1686.

Cleland, J.G., Bristow, M.R., Erdmann, E., Remme, W.J., Swedberg, K., Waagstein, F., 1996. Beta-blocking agents in heart failure. Should they be used and how? Eur. Heart J. 17, 1629 1639.

Cournot, A., Lim, C., Duchier, J., Safar, M., 1992. Hemodynamic effects of carvedilol after acute oral administration in hypertensive and normal subjects. J. Cardiovasc. Pharmacol. 19, S35-39.

Crespi, C.L., Miller, V.P., Penman, B.W., 1997. Microtiter plate assays for inhibition of human, drug-metabolizing cytochromes P450. Anal. Biochem. 248, 188-190.

Cummins, C.L., Jacobsen, W., Benet, L.Z., 2002. Unmasking the dynamic interplay between intestinal P-glycoprotein and CYP3A4. J. Pharmacol. Exp. Ther. 300, 1036-1045.

DasGupta, P., Broadhurst, P., Lahiri, A., 1991. The effects of intravenous carvedilol, a new multiple action vasodilatory betablocker, in congestive heart failure. J. Cardiovasc. Pharmacol. 18, S12-16.

Dixon, R.A., Steel, C.L., 1999. Flavonoids and isoflavonoids - a gold mine for metabolic engineering. Trend Plant. Sci. 4, 394400.

Dzubák, P., Hajdúch, M., Gazák, R., Svobodová, A., Psotová, J., Walterová, D., Sedmera, P., Kren, V., 2006. New derivatives of silybin and 2,3-dehydrosilybin and their cytotoxic and P-glycoprotein modulatory activity. Bioorg. Med. Chem. 14, 37933810 .
Feuerstein, G.Z., Bril, A., Ruffolo, R.R.Jr., 1997. Protective effects of carvedilol in the myocardium. Am. J. Cardiol. 80, 41L-45L.

Frishman, W.H., 1998. Carvedilol. N. Engl. J. Med. 339, 17591765.

Hampton, J.R., 1996. Beta-blockers in heart failure--the evidence from clinical trials. Eur. Heart J. 17, 17-20.

Kaminsky, L.S., Fasco, M.J., 1991. Small intestinal cytochromes P450. Crit. Rev. Toxicol. 21, 407-422.

Katiyar, S.K., Korman, N.J., Mukhtar, H., Agarwal, R., 1997. Protective effects of silymarin against photocarcinogenesis in a mouse skin model. J. Natl. Cancer Inst. 89, 556-566.

Kolars, J.C., Schmiedlin-Ren, P., Schuetz, J.D., Fang, C., Watkins, P.B., 1992. Identification of rifampin-inducible P450IIIA4 (CYP2C9) in human small bowel enterocytes. J. Clin. Invest. 90, 1871-1878.

Kosina, P., Maurel, P., Ulrichová, J., Dvorák, Z., 2005. Effect of silybinin and its glycosides on the expression of cytochromes P450 1A2 and 3A4 in primary cultures of human hepatocytes. J. Biochem. Mol. Toxicol. 19, 149-153.

Lewis, D.F.V., 1996. Cytochrome P450. Substrate specificity and metabolism. In: Cytochromes P450. Structure, Function, and Mechanism. Taylor \& Francis: Bristol. 122-123.

Lund-Johansen, P., Omvik, P., Nordrehaug, J.E., White, W., 1992. Carvedilol in hypertension: effects on hemodynamics and 24hour blood pressure. J. Cardiovasc. Pharmacol. 19, S27-34.

McTavish, D., Campoli-Richards, D., Sorkin, E.M., 1993. Carvedilol. A review of its pharmacodynamic and pharmacokinetic properties, and therapeutic efficacy. Drugs 45, 232-58.

Morazzoni, P., Bombardelli, E., 1995. Silybum marianum (fitoterapia). Fitoterapia 66, 3-42.

Morgan, T., 1994. Clinical pharmacokinetics and pharmacodynamics of carvedilol. Clin. Pharmacokinet. 26, 335-346.

Neugebauer, G., Akpan, W., von Mollendorff, E., Neubert, P., Reiff, K., 1987. Pharmacokinetics and disposition of carvedilol in humans. J. Cardiovasc. Pharmacol. 11, S85-88.

Neugebauer, G., Neubert, P., 1991. Metabolism of carvedilol in man. Eur. J. Drug Metab. Pharmacokinet. 16, 257-260.

Nijveldt, R.J., van Nood, E., van, Hoorn, D.E., Boelens, P.G., van Norren, K., van Leeuwen, P.A., 2001. Flavonoids: a review of probable mechanisms of action and potential applications. Am. J. Clin. Nutr. 74, 418-425.

Ohnishi, E., Bannai, H., 1993. Quercetin potentiates TNF-induced antiviral activity. Antiviral Res. 22, 327-331.

Oldham, H.G., Clarke, S.E., 1997. In vitro identification of the human cytochrome $\mathrm{P} 450$ enzymes involved in the metabolism of $\mathrm{R}(+)$ - and S(-)-carvedilol. Drug Metab. Dispos. 25, 970977.

Saeki, T., Ueda, K., Tanigawara, Y., Hori, R., Komano, T., 1993. Pglycoprotein-mediated transcellular transport of MDR-reversing agents. FEBS. Lett. 324, 99-102.

Takahama, U., 1985. Inhibition of lipoxygenase-dependent lipid peroxidation by quercetin: mechanism of antioxidative function. Phytochemistry 24, 1443-1446.

von Mollendorff, E., Abshagen, U., Akpan, W., Neugebauer, G., 
Schroter, E., 1986. Clinical pharmacologic investigations with carvedilol, a new beta-blocker with direct vasodilator activity. Clin. Pharmacol. Ther. 39, 677-682.

Zhao, J., Lahiri-Chatterjee, M., Sharma, Y., Agarwal, R., 2000. Inhibitory effect of a flavonoid antioxidant silymarin on benzoyl peroxide-induced tumor promotion, oxidative stress and inflammatory responses in SENCAR mouse skin. Carcinogenesis $21,811-816$.
Zharghi, A., Foroutan, S.M., Shafaati, A., Khoddam, A., 2007. Quantification of carvedilol in human plasma by liquid chromatography using fluorescence detection: Application in pharmacokinetic studies. J. Pharm. Biomed. Anal. 44, 250-253. Zuber, R., Modrianský, M., Dvorák, Z., Rohovský, P., Ulrichová, J., Simánek, V., Anzenbacher, P., 2002. Effect of silybinin and its congeners on human liver microsomal cytochrome P450 activities. Phytother. Res. 16, 632-638. 